\title{
BMJ Open Diet and physical activity for children's health: a qualitative study of Nepalese mothers' perceptions
}

\author{
Natalia Oli, ${ }^{1,2}$ Abhinav Vaidya, ${ }^{1}$ Madhusudan Subedi, ${ }^{3}$ Gabriele Eiben, ${ }^{4}$ \\ Alexandra Krettek ${ }^{2,5,6}$
}

To cite: Oli N, Vaidya A Subedi M, et al. Diet and physical activity for children's health: a qualitative study of Nepalese mothers' perceptions. BMJ Open 2015;5:e008197.

doi:10.1136/bmjopen-2015008197

\section{- Prepublication history is} available. To view please visit the journal (http://dx.doi.org/ 10.1136/bmjopen-2015008197).

Received 15 March 2015 Revised 4 August 2015 Accepted 12 August 2015

CrossMark

For numbered affiliations see end of article.

Correspondence to Dr Natalia Oli; natalia.oli@gu.se

\section{ABSTRACT}

Objectives: Non-communicable diseases account for $50 \%$ of all deaths in Nepal and $25 \%$ result from cardiovascular diseases. Previous studies in Nepal indicate a high burden of behavioural cardiovascular risk factors, suggesting a low level of knowledge, attitude and practice/behaviour regarding cardiovascular health. The behavioural foundation for a healthy lifestyle begins in early childhood, when mothers play a key role in their children's lives. This qualitative study, conducted in a Nepalese peri-urban community, aimed to explore mothers' perception of their children's diet and physical activity.

Design: We notated, tape-recorded and transcribed all data collected from six focus group discussions, and used qualitative content analysis for evaluation and interpretation.

Setting: The study was conducted in the JhaukhelDuwakot Health Demographic Surveillance Site in the Bhaktapur district of Nepal.

Participants: Local health workers helped recruit 61 women with children aged 5-10 years. We distributed participants among six different groups according to educational status.

Results: Although participants understood the importance of healthy food, they misunderstood its composition, perceiving it as unappetising and appropriate only for sick people. Furthermore, participants did not prioritise their children's physical activities. Moreover, mothers believed they had limited control over their children's dietary habits and physical activity. Finally, they opined that health educational programmes would help mothers and recommended various intervention strategies to increase knowledge regarding a healthy lifestyle.

Conclusions: Our data reveal that mothers of young children in a peri-urban community of Nepal lack adequate and accurate understanding about the impact of a healthy diet and physical activity. Therefore, to prevent future cardiovascular disease and other noncommunicable diseases among children, Nepal needs health education programmes to improve mothers' cardiovascular health knowledge, attitude and behaviour.

\section{Strengths and limitations of this study}

- This study reports for the first time the perceptions of Nepalese mothers with young children regarding behavioural risk factors such as diet and physical activity, which are important determinants of non-communicable diseases.

- Our qualitative research approach ensured that study participants generated the views reported here.

- Stratifying focus groups according to educational level allowed us to compare participants' views according to educational background.

- Participants were recruited purposively and belonged to one particular region of Nepal, hence the study population cannot represent all mothers of Nepal.

- Since medical doctors conducted the focus group discussions, some participants (particularly those with less education) may have felt inhibited about communicating openly.

\section{INTRODUCTION}

Non-communicable diseases (NCDs) are the leading cause of deaths globally and occur most commonly in low-income and middle-income countries. ${ }^{12}$ In Nepal, a lowincome country, NCDs account for $50 \%$ of all deaths; half of those result from cardiovascular diseases (CVDs). ${ }^{3}$

Unhealthy diets and low physical activity are proven and preventable risk factors for NCDs. ${ }^{4-6}$ Rapidly changing lifestyles, currently shifting towards high energy-dense diets and low levels of physical activity, increase the prevalence of diet-related chronic diseases both globally ${ }^{7}{ }^{8}$ and in Nepal. ${ }^{9-11}$ Moreover, other cardiovascular behavioural risk factors (eg, tobacco consumption) are also prevalent in Nepal. ${ }^{12}$

Established in 2010, the Jhaukhel-Duwakot Health Demographic Surveillance Site (JD-HDSS) is located in the Bhaktapur 
district, $13 \mathrm{~km}$ east of Kathmandu, the capital city. JD-HDSS aims to collect longitudinal data on the health status of this peri-urban community, with particular focus on cardiovascular health. ${ }^{13}$ The prevalence of cardiovascular risk factors such as low fruit and vegetable consumption in JD-HDSS is high, ${ }^{14}$ and cardiovascular health knowledge, attitude and practice/behaviour is poor. ${ }^{15}$ Although unhealthy diet is a known cause of CVDs, our in-depth interviews with people affected by cardiometabolic diseases revealed frequent common misconceptions regarding the components of a healthy diet. ${ }^{16}$ Furthermore, interviewees rarely mentioned physical inactivity as a risk factor. Additionally, participants' low perception of susceptibility towards CVDs and the benefit of specific action, as described in the health belief model, ${ }^{17}$ were common reasons for continuing unhealthy lifestyles. ${ }^{16}$ Indeed, the health belief model, along with the social cognitive theory, can be applied here to explore cardiovascular health-related behaviour of the community. The health belief model suggests that an individual's willingness to modify his/her own behaviour is based on constructs such as perceived susceptibility, perceived severity, perceived benefit and perceived barriers. ${ }^{17}$ Additionally, the social cognitive theory states that there is an interaction between personal factors of the individual, environmental factors and human behaviour, where each influences the others. ${ }^{17}$

Although the atherosclerotic process begins in childhood, children are rarely considered at risk for CVDs, ${ }^{18} 19$ a misconception that also extends to Nepal. ${ }^{16}$ However, an alarming increase in both obesity and type II diabetes among children worldwide suggests that preventive programmes should target this population. ${ }^{20}$ Currently, Nepal lacks national data on childhood obesity. However, given the high prevalence of behavioural risk factors and an increasing trend towards obesity among adults, ${ }^{21}$ it is likely that the current adoption of unhealthy behaviour by Nepalese children may increase childhood obesity. ${ }^{22}$

Parents are largely responsible for creating their children's environment and lifestyle, and the behavioural foundations laid during childhood affect offspring throughout their lives. ${ }^{23}$ Parental knowledge about nutrition, and parent's feeding practices, cooking skills, and household's access to food and its availability, along with children's individual characteristics, all contribute to the food environment that affects children's dietary habits. $^{22}{ }^{24}$ In this regard, good parental knowledge about nutrition associates with healthier dietary habits in children (eg, higher consumption of vegetables and fruits, and lower consumption of fried food and sweets). ${ }^{25}{ }^{26}$ Further, parental support associates positively with children's physical activity. ${ }^{27}$ Since mothers in Nepal are traditionally responsible for their children's lifestyle, ${ }^{28}$ improving their understanding of healthy diet and physical activity may exert a positive influence on children's behaviour. Therefore, focusing on mothers in this context is important.
Considering the poor cardiovascular health literacy and high prevalence of cardiovascular risk factors in the general population of Duwakot and Jhaukhel, ${ }^{15}$ health education programmes appear crucial. Indeed, successful intervention requires programmes tailored not only to local needs and available resources but also to the targeted population. ${ }^{29}$ Therefore, we designed this qualitative study to explore mothers' perceptions of their school age children's lifestyle, particularly regarding diet and physical activity, aiming to increase understanding of the facilitators and barriers for maintaining healthy behaviour, and the perceived roles of mothers in developing healthy lifestyles for their children. In addition, we aimed to explore the relevance and preferred choice of health educational intervention. This knowledge may be useful for developing future educational programmes to help mothers in peri-urban communities improve children's diet and physical activity.

\section{METHODS}

\section{Study setting and participants}

We conducted focus group discussions (FGDs) between April and August 2013 in the JD-HDSS, which was established in 2010. JD-HDSS comprises two adjacent and rapidly urbanising villages, Jhaukhel and Duwakot; these villages share similar geoecological, ethnic and cultural characteristics. According to the baseline census conducted in 2010, JD-HDSS had 2712 households and a total population of $13669 .^{13}$

We recruited participants by convenient sampling, enrolling women with school-age children no younger than 5 years of age. Since education influences knowledge level and perceptions of health, ${ }^{15} 30$ we stratified participants into three categories: no formal education, education up to grade 10 (ie, secondary level) and higher education, (ie, higher than grade 10). We predetermined the date, time, venue and educational status of women for each FGD. After ensuring that we included different localities within Duwakot and Jhaukhel, local health workers prepared a list of possible participants and contacted them a few days prior to each FGD. Altogether, 61 women participated in the study, and the number of participants in each FGD varied from 9 to 12 . All women participated until the end of the discussions.

\section{Data collection}

We developed an FGD guide based on relevant publications ${ }^{31-34}$ and discussions within our research group. We pretested our FGD guide in Changunarayan, a neighbouring and socioculturally similar village to JD-HDSS. We made additional changes to the FGD guide after pretesting and also during the progression of the FGDs. The guide contained broad and open-ended questions for the areas of interest. When necessary, the FGD moderator asked probing questions during the discussions to aid deeper exploration into the issues.

We conducted two FGDs for each category of educational status (ie, six FGDs) and conducted one FGD per 
day. Each FGD lasted 2-3 h. The first author (NO) moderated all FGDs. A medical graduate by background, NO is currently a PhD student at the University of Gothenburg, Sweden; her area of study involves health promotion in cardiovascular health issues, particularly involving mothers and children. She previously conducted qualitative studies using FGDs during her Masters of Public Health degree and also conducted in-depth interviews for her current PhD studies. She was assisted by the second author (AV), and a research assistant took notes and handled the tape-recordings. AV, a recent $\mathrm{PhD}$ graduate of the University of Gothenburg, also has experience in cardiovascular health research and qualitative studies from his doctoral studies.

Venues for the six FGDs were based primarily on accessibility and comfort of the participants. We conducted three FGDs in the meeting room of Nepal Medical College Community Hospital in Jhaukhel, two in private homes of the local health workers and one in the meeting room of the Duwakot health post. To encourage open communication during the discussions, we ensured that local health workers or other people not involved in the research were not present in the room. Each FGD began informally with greetings and personal introductions. The respondents in each group knew their fellow participants well and they conversed freely with one another. All conversations during the FGDs were in the Nepali language.

At the outset, the moderator clearly explained the objectives of the discussion and briefed all participants on the ground rules, both during and after each session. The moderator asked participants about their understanding of healthy behaviour, and also asked if they thought there is a relationship between health-related behaviours and CVD. Next, the discussion shifted towards participants' perception of their own roles in family health issues. The moderator then inquired about the participants' knowledge, experiences and perceptions of practices regarding dietary habits and physical activity in their family, especially in young children. In particular, the discussions probed mothers' knowledge of their children's food preferences and leisure-time activities as well as the perceived role of parents, including parental control (if any) over the children's choices. Finally, participants were asked about the need and utility of any intervention they thought may influence their children's dietary habits and physical activity.

At the end of the each FGD, the moderator summarised the discussion and answered all questions that arose during the discussion. The note-taker detailed all aspects of the discussion, including non-verbal communications. In addition to textual information, $\mathrm{NO}$ and $\mathrm{AV}$ used these non-verbal communications to enrich the results section. They discussed the findings after each FGD and noted the important points. They continued the FGDs until data saturation occurred (ie, when no additional codes were identified).

\section{Data analysis}

$\mathrm{NO}$ and AV analysed data manually and applied qualitative content analysis techniques. ${ }^{35}{ }^{36}$ First, an experienced translator listened to all audio recordings, transcribed the data verbatim and translated it into the English language. Next, NO and AV discussed the available data from notes, transcripts and the original recordings. After reaching consensus, they created subcategories and categories from the extracted meaningful units (table 1).

Table 2 provides an example of this abstraction process. During analysis, we identified any differences in opinions according the mothers' education level.

\section{Ethical aspects}

We obtained verbal consent from all respondents for their participation, and for audio recording and note taking. Respondents were informed that they could refuse participation in any part of the discussion or leave the FGD whenever they wished. All respondents received a boxed lunch and a travel allowance. All FGD data, including notes and tape-recordings, were kept safely in the researchers' office, without access to any external person.

Table 1 Qualitative content analysis: categories and subcategories

\begin{tabular}{|c|c|}
\hline Categories & Subcategories \\
\hline Concept of health linked to personal behaviour & Maintaining cleanliness, eating fresh and healthy food \\
\hline Mothers' general perceptions regarding healthy and & 'Outside' food is fast food \\
\hline unhealthy food & Mothers believe that healthy food is not tasty \\
\hline Mothers' perceptions about their children's diet and & Children prefer fast food to homemade food \\
\hline physical activity & Mothers do not prioritise their children's physical activity \\
\hline Perceived self-ability to control children's behaviour & $\begin{array}{l}\text { Mothers are responsible for their family's lifestyle } \\
\text { Mothers cannot control their children }\end{array}$ \\
\hline Perceived barriers for healthy lifestyle in children & $\begin{array}{l}\text { Senior family members do not like healthy food } \\
\text { Environmental factors hinder children's healthy behaviour }\end{array}$ \\
\hline Perceived facilitators & $\begin{array}{l}\text { Educating mothers on healthy lifestyles can further improve their } \\
\text { authority in the family } \\
\text { It is better to establish healthy behaviour when children are young } \\
\text { Mothers' expressed needs regarding educational intervention }\end{array}$ \\
\hline
\end{tabular}


Table 2 Example of extracting meaningful units, their condensation and abstraction

\begin{tabular}{llllll}
\hline FGD & Meaningful units & $\begin{array}{l}\text { Condensed } \\
\text { meaningful units }\end{array}$ & Codes & Subcategories & Categories \\
\hline 1 & $\begin{array}{l}\text { Fast food is unhealthy and } \\
\text { available outside (eg, in } \\
\text { restaurants or the market) }\end{array}$ & $\begin{array}{l}\text { Outside food is fast } \\
\text { food, which is } \\
\text { unhealthy }\end{array}$ & $\begin{array}{l}\text { Fast food is } \\
\text { unhealthy }\end{array}$ & $\begin{array}{l}\text { 'Outside' food is fast } \\
\text { food }\end{array}$ & $\begin{array}{l}\text { Mother's general } \\
\text { perceptions regarding } \\
\text { healthy and unhealthy } \\
\text { food }\end{array}$ \\
$\begin{array}{l}\text { Healthy food is not tasty and } \\
\text { is usually cooked only for } \\
\text { sick members of the family }\end{array}$ & $\begin{array}{l}\text { Healthy food is only } \\
\text { for sick people }\end{array}$ & $\begin{array}{l}\text { Mothers' } \\
\text { beliefs }\end{array}$ & $\begin{array}{l}\text { Mothers believe that } \\
\text { healthy food is not } \\
\text { tasty }\end{array}$ & & \\
\hline FGD, focus group discussion. & & &
\end{tabular}

\section{RESULTS}

\section{Sociodemographic characteristics}

Table 3 describes the characteristics of the six FGDs and their participants. We purposely selected participants according to educational status: no formal education, up to grade 10 (secondary level) and higher education (higher than grade 10).

Educational background did not affect participants' knowledge regarding healthy diet and physical activity. However, we observed some differences in how participants conveyed information. Compared to women with more education, less-educated women were shy, had difficulty expressing knowledge and often showed signs of low self-esteem and confidence during the FGDs.

\section{Concept of health linked to personal behaviour}

All participants understood that personal behaviour affects health and they opined that healthy behaviour helps maintain good health. Most emphasised that their houses are clean (ie, they maintain good personal hygiene, consume safe drinking water and protect food from insects). All participants viewed alcohol consumption and smoking as habits that should be avoided to remain healthy. Many women linked alcohol and smoking with heart diseases, and one participant said: 'Drinking habit, smoking habit...they cause heart disease also, it is due to stress... and tension' (FGD 3). Another participant observed: 'Health means...considering personal hygiene... One should not consume alcohol...or cigarettes...prefer to eat the vegetables' (FGD 6).
The mothers pointed out that a healthy diet is important for maintaining their own health and most identified fat and salty food as the main causes of CVD. One participant linked meat consumption and spicy food to heart diseases, saying: 'Too much fat...too much "masala" [spices] ... they lead to heart diseases' (FGD 6). Another mother commented: 'I'm eating oily...spicy... meats...fish...everything...pressure is high or low... I don't know' (FGD 4).

Compared to mothers with less education, educated participants described unhealthy diet as a risk factor for heart diseases. Some mothers mentioned that consumption of fruits and vegetables is healthy behaviour. Almost all participants viewed homemade food as healthy, irrespective of preparation. They also mentioned regular eating habits, and avoiding pesticides and antibiotics in food as healthy food behaviour.

Participants did not spontaneously link physical activity to healthy behaviour. However, probing questions revealed that they identified physical activity as 'good for health' and having a 'protective effect on the heart'. One mother said: 'Yes...those who are lazy...they will get heart disease' (FGD 3).

\section{Mothers' general perceptions regarding healthy and} unhealthy food

\section{'Outside' food is fast food}

Most participants confidently said that fast foods are 'those foods that are available outside, like in restaurants or in the market'. When asked to name fast food items, they mentioned instant noodles, momo (dumplings), chowmein

\begin{tabular}{|c|c|c|c|c|c|c|}
\hline FGD & Village & $\begin{array}{l}\text { Participants, } \\
\mathrm{n}=61\end{array}$ & $\begin{array}{l}\text { Age range } \\
\text { (years) }\end{array}$ & $\begin{array}{l}\text { Educational } \\
\text { status }\end{array}$ & $\begin{array}{l}\text { Children per participant } \\
\text { (median) }\end{array}$ & $\begin{array}{l}\text { Age range of } \\
\text { children (years) }\end{array}$ \\
\hline 1 & Duwakot & 11 & $23-38$ & $\begin{array}{l}\text { Higher than grade } \\
10\end{array}$ & 1 & $3-8$ \\
\hline 2 & Duwakot & 12 & $21-38$ & Up to grade 10 & 2 & $5-17$ \\
\hline 3 & Duwakot & 7 & $22-36$ & No formal education & 2 & $4-16$ \\
\hline 4 & Jhaukhel & 10 & $21-36$ & Up to grade 10 & 2 & $5-15$ \\
\hline 5 & Jhaukhel & 12 & $20-32$ & No formal education & 2 & $4-18$ \\
\hline 6 & Jhaukhel & 9 & $21-35$ & $\begin{array}{l}\text { Higher than grade } \\
10\end{array}$ & 1 & $5-13$ \\
\hline
\end{tabular}

FGD, focus group discussion. 
(stir-fried noodles), biscuits, burgers, kurkure (packaged puffs in corn with salt and spices), cheese balls (packaged puffs in corn and cheese flavours, targeting mainly children) and pani-puri (a street snack that consists of a round, hollow deep-fried wheat bread filled with a mixture of flavoured water, tamarind chutney, potato, etc).

Almost all participants said that fast food is bad for the health of adults as well as children. However, they could not elaborate on how fast food affects health. One mother stated: 'We know that the product that is produced at home is healthy... and market products are unhealthy' (FGD 1).

\section{Mothers believe that healthy food is not tasty}

Although most respondents emphasised the importance of healthy food, they also described such food as unappetising. This was one reason they usually cook healthy food (ie, low-salt content or less sugar) only for family members with health problems such as hypertension or diabetes. After keeping some food aside for sick family members, mothers usually added more salt and oil to 'make the food tastier' for the rest of the family. Regardless of educational background, all participants agreed that people should consume less salty and oily food, but only after disease has been diagnosed.

\section{Mothers' perceptions about their children's diet and physical activity \\ Children prefer fast food to homemade food}

Most mothers said their children prefer fast food such as instant noodles, cookies, chips, cheese balls, doughnuts, chowmein, choco-fun (a chocolate flavoured bar) and panipuri. Many participants worried about their children's food preferences because they understood that such food is unhealthy. One mother said:

I have to put extra sugar in his milk...otherwise (he) won't drink...wants to eat chowmein...doesn't eat food in the morning and evening [regular main meal]...doesn't like vegetables...eats fruits, creamy biscuits, 'chau-chau' [instant noodles]...prefers 'pasal ko khana' [readymade food available in shops] than home-food. [FGD 4]

Participants reported that even if children like homemade food, they prefer it to be oily, spicy and fried. One mother said: 'My child likes oily and spicy food more... fried food...she likes curry (vegetables cooked in water) less...previously, I used to make fried food...so she likes it more...' (FGD 5). In addition, participants said children's favourite drinks were aerated beverages such as Fanta and Coke, tetra-packed juices such as 'Real' juice and fruit-flavoured drinks such as Tang.

Some respondents said their children like homemade food because their family members do not eat fast food and they do not encourage their children to eat it. Such statements were made mainly by mothers with younger children. One mother reported: 'My children...they don't like fast foods ('bahira ko khana') because...they know they are bad' (FGD 1).

\section{Mothers do not prioritise children's physical activity}

When asked how their children spend their leisure time, most mothers said they 'Don't have time, they need to do homework...' Most mothers prioritised their children's homework and did not pay adequate attention to physical activity. One mother said: 'It's my wish that...my child studies well' (FGD 2); another said: '(I tell them) don't play...don't watch TV...study...I scold them to read... and study' (FGD 3). In addition, many participants considered playtime an excuse to have fun and to skip homework. One mother commented: 'My son...he goes off to play immediately whenever he gets time... while the daughter she stays home and studies' (FGD 2).

Thus, most children spent their free time inside, either doing homework or watching cartoons and playing computer games. During school holidays, many children watched TV or played computer games all day. One mother said: 'They watch a lot of TV during holidays...even during study time... they usually watch TV for 2 h' (FGD 4).

Some children, usually boys, enjoyed playing active outdoor games such as football. In contrast, girls preferred staying home and rarely participated in active games. Moreover, many participants said they do not allow their children to play outside for safety reasons. One mother said: 'If they play more, they'll be injured... [they] can break limbs...so I don't want them to play outside more...' (FGD3). Another commented about 'All these speeding bikes, cars.... It is dangerous for children to play outside...' (FGD 4).

\section{Perceived self-ability to control children's behaviour Mothers are responsible for their family's lifestyle}

All participants said they were responsible for shaping their family's lifestyle, including those of their children. They usually decided on what food to cook and how to prepare it, and also decided how to run the house and care for their children. One mother said: 'What and how my children eat is in my hands...my husband doesn't care much...I give more attention...' (FGD 2); another said that the 'Male's role is to bring money... and female's role is to maintain family health...like diet and cleanliness of the house...' (FGD 4). Another observed: 'mothers have a bigger role in their hands...if children get spoilt...then it will be the fault of the mothers...' (FGD 2).

\section{Mothers cannot control their children}

Although participants realised that that they play a large role in shaping their children's lifestyles, only a few controlled their children's consumption of fast food. In fact, many mothers who admitted that their children have an unhealthy diet said that they do not try to change this because they perceive it as being impossible. One mother said: '[We] have to give in even if we don't want ("nachahanda nachahandai")...it's not possible to control...we are compelled to give what they want to eat' (FGD 2). Another participant commented: 'I do not 
know how to stop my child from eating fast food...he doesn't like rice and vegetables, he always asks for money to buy something outside in the local shops...' (FGD 4).

However, some participants admitted it was their fault that their children developed a preference for fast food. One mother said: 'It was more convenient for me to give money and send my child to a shop nearby...when I didn't have time to cook or was feeling lazy to cook...' (FGD 4). Another commented: 'When they are small, it is easy to control them...but the older they became...it's more difficult...'(FGD 4).

Participants shared similar thoughts regarding their children's physical activity. Mothers often chose what was easiest for themselves over what was better for their children. Many mothers acknowledged that watching too much TV is bad for their children's health, but some said that it is more convenient if the child watches cartoons at home rather than playing outside, which can be unsafe. One participant said: 'She is watching TV... and I know she is nearby...but outside is not safe for children...' (FGD 4).

Some participants reported difficulty controlling screen time, and one mother said her children 'Always do whatever they want...' (FGD 2). Mothers who successfully limit screen time mentioned electricity load shedding as a factor, and one mother commented: 'He is watching cartoons after homework is done...he can watch several hours until the electricity goes off because of load-shedding ...' (FGD 2). However, some participants thought that it was fine for children to watch TV because it is a good source of information. One mother said: 'They need to watch it also...they need to learn things...' (FGD 3).

Participants reported that they do not prioritise sharing leisure time with their children. Further, they did not think that parents should encourage their children to engage in physical activity.

\section{Perceived barriers for healthy lifestyle in children}

Senior family members do not like healthy food

One of the mentioned barriers for developing healthy lifestyle of the children was lack of decision-making power regarding food in joint families. In such families, daughters-in-law are often responsible for cooking but must cater to the taste preferences of senior family members, which may not always be healthy. One woman said: 'I know that too much salt and oil in the food is bad for health, but my father-in-law likes such food... and we live with them (in-laws)...so I need to cook this way...' (FGD 6).

Another perceived barrier was grandparents' tendency to spoil their grandchildren by buying them sweets and candies. One mother commented: 'I am trying to give my daughter homemade food that is good for her...but they (grandparents)...when visiting us, always try to buy "outside" food for her...chocolates, chips...things like these...' (FGD 3).
Environmental factors hinder children's healthy behaviour

Most participants mentioned TV advertisements as an important factor that affects children's dietary choices. Children ask their mothers to buy particular food items (eg, chips, cheese balls, chocolates and soft drinks) that they had seen on TV commercials. Participants admitted that they succumb to their children's pestering and buy unhealthy food. One mother said: 'My child wants to eat what is shown on TV...boost...horlicks (supplementary nourishment drinks)' (FGD 1).

Mothers also perceived the absence of children's playgrounds as an important barrier for healthy lifestyle, saying that children lack a safe place to play.

\section{Perceived facilitators}

Educating mothers on healthy lifestyles can further improve their authority in the family

Irrespective of educational level, many mothers said that knowing more about healthy diet and physical activity would help them improve their children's lifestyle. Even mothers who needed to consider senior family members' opinions, said they would be able to apply such knowledge: One participant commented: 'I think they (in-laws) will listen to me more...if I get some training in cooking in healthy ways' (FGD 1).

\section{It is better to establish healthy behaviour when children are young}

During FGDs, many mothers appeared confused regarding the appropriate age to establish healthy behaviour in their children. Many thought the proper age would be 15-16 years, because they thought this is the age when children begin to accept and understand information regarding health, and make decisions regarding healthy lifestyles. However, probing questions elicited some opinions that parents should establish healthy behaviours earlier, when children are more easily influenced. One mother said: '...we have to teach them before they stop listening to us... at age 7-8 it is already difficult ...' (FGD 2).

\section{Mothers' expressed needs regarding educational intervention} Irrespective of educational level, participants acknowledged the importance of improving their current knowledge on diet and physical activity. Although they were enthusiastic that the research team might help them improve their knowledge through an intervention programme, their opinions varied on the preferred channel of receiving information. Many participants thought that video would be effective, while others suggested educational classes given by medical personnel. Although some participant said doctors were better able deliver health information, others felt they would be more comfortable communicating with a trained local person. One participant said: 'Health workers from the village should create awareness in the community' (FGD 5). 


\section{DISCUSSION}

This qualitative study explored the perceptions of periurban Nepalese mothers of young children, regarding healthy behaviours such as diet and physical activity. Our results show that most respondents linked healthy behaviour to hygiene and fresh food, possibly due to the prevalent problems regarding safe drinking water and sanitation in Nepal. ${ }^{37} 38$ Highlighting food freshness can be linked to traditional Nepalese beliefs that "bashi khana" (stale food) is bad for health. ${ }^{39}$ Combined with Nepal's hot climate, the past unavailability of refrigerators could have contributed to such beliefs. In addition, because many health programmes (eg, hand washing) in Nepal focus on preventing communicable disease, ${ }^{40}$ people frequently link healthy behaviour with protection against infection. In the present study, most participants mentioned alcohol and smoking hazards. Although all mothers acknowledged the importance of healthy diet, they misunderstood the composition of healthy diets. For example, most mothers thought that all 'market food' (ie, food available in the market either as fast food or packaged food) is unhealthy and all homemade food is healthy, irrespective of cooking method.

Although participants stated that health depends on personal behaviour, they did not seem to search for ways to improve their own behaviour and expected health personal to give advice. This attitude suggests an external locus of control, ${ }^{41}$ which is common in the Nepalese population. ${ }^{16}$ This attitude was also evident in the participants' tendency to look for external facilitating factors for healthy behaviour rather than seeking factors within themselves or in their surroundings. Further, participants thought that individuals should improve their dietary habits only after becoming ill. English and Chilean women share similar views. ${ }^{42}{ }^{43}$ Also, most of our participants reported that they cook separately (and healthily) only for family members who are sick. Despite their knowledge that oily and salty food is harmful to the heart, mothers appeared unaware of their own disease risk and hence maintained an unhealthy diet.

Mothers expressed concern about their difficulty in controlling children's behaviour. They felt that children were strongly influenced by peers and television advertisements, and did not listen to their mothers. Other studies identified similar concerns. ${ }^{33} 44$ Most participants confessed that they had stopped trying to make their children eat healthy food, an issue also reported among Norwegian-Pakistani women. ${ }^{45}$ Our participants perceived that they had a low level of control over their children's diet and physical activity, a view further supported by their opinion that electricity load-shedding provides a better controlling mechanism for children's screen time.

Along with perceived ability and skills to perform required actions (self-efficacy), an individual's beliefs that he/she can control events affecting him/her (locus of control) influences his/her perception of control. ${ }^{46}$ Thus, perceived control is an individual's perception that her/his actions can accomplish a desired outcome.
Furthermore, our participants' external locus of control and low self-efficacy result in a low level of perceived control over their children's diet. In fact, low perceived control results in low motivation to enact the behaviour of interest. ${ }^{46}$ Therefore, perceived lack of control may explain mothers' insufficient intentions and actions to control their children's diets.

Other reasons for parental failure to control their children's diet include inadequate knowledge of nutrition and lack of motivation to ensure a healthy diet. ${ }^{44}$ Most of our participants blamed this parental failure on their children's unhealthy preference for fast food. Moreover, although all mothers were highly concerned about their children's health, many considered children's preference for fast food as normal. Interestingly, many mothers were primarily concerned about the health hazards of solid fast foods and did not mention any negative effects from sweetened soft drinks.

However, some respondents admitted that it was their own fault that their children preferred market food over homemade food. This attitude largely reflected a convenience factor. Compared to cooking healthy food, mothers found it easier to buy fast food or give the child money to eat outside. Additionally, the mothers' strong belief that healthy food is not appetising can, from early childhood, be transferred to their children. Other studies have reported similar findings. ${ }^{45} 47$ Along with unhealthy food consumption by the family and preparing healthy food only for sick family members, this attitude can make children adopt an unhealthy diet. A study in Mexico reported that mothers' food preferences influenced children's food preferences in children as young as 3-4 years of age. ${ }^{48}$ Indeed, the family food environment plays a crucial role in establishing a child's dietary lifestyle. ${ }^{24}$

Similar to a US study of rural women in West Virginia, ${ }^{31}$ most of our participants regarded the food preferences of senior family members a major barrier towards healthy lifestyle. Other studies support these findings. ${ }^{43}$ In addition, many mothers accused family members of interfering with their efforts to control the quality of their children's diets (eg, buying candy for the children). Young mothers in Western Australia reported the same barrier. ${ }^{44}$ However, many participants in our study did not perceive availability of unhealthy food in the market as a barrier for healthy lifestyle but rather considered it normal.

Compared to other studies, ${ }^{50}{ }^{51}$ our participants did not prioritise physical activity. In fact, none of them even mentioned physical activity while talking about healthy behaviour. Only probing questions elicited responses that linked physical activity to health. Being physically inactive themselves, ${ }^{52}$ they did not encourage or participate in their children's physical activity.

Behavioural changes in a community require an understanding of behaviour theories and an ability to apply such theories while developing an intervention. Hence, theories other than the aforementioned locus of control 
theory apply in our context. According to the health belief model, ${ }^{17}$ mothers who do not perceive themselves at risk underestimate the consequences of unhealthy behaviour and do not recognise the benefits of behavioural changes. Such attitudes can negatively influence children, as explained by the social cognitive theory (ie, behaviours are adopted through observational learning and role modelling). However, positively applied lifestyle preferences can motivate children towards a healthier diet and levels of physical activity. ${ }^{53}$ Apart from these facilitating factors, researchers must consider the poor cardiovascular health literacy of the community as an important hindrance towards heart-healthy behaviour. ${ }^{15}$

\section{Strengths and limitations}

To the best of our knowledge, the present study is the first qualitative study in Nepal to explore mothers' perceptions regarding the diet and physical activity of their school-age children. We stratified women into different groups according to education level, thus ensuring that we extracted information from diverse educational levels. Nonetheless, less-educated respondents displayed difficulty expressing their views, possibly influencing the results. Such behaviour is partly explained by Nepalese culture and traditions. Less-educated women have low decision-making power in their families and are not accustomed to expressing their knowledge and opinions to others, especially to those with higher educational or social status. Indeed, this is a limitation of our study. Additionally, both researchers who conducted the FGDs are medical doctors. A paternalistic model of the doctorpatient relationship is common in Nepal, possibly influencing communication during data collection. However, at the beginning of the discussion, when we felt awkwardness in the less educated among respondents, we tried to make them more comfortable by creating a friendly environment and good rapport, and by beginning with informal light talks before returning to the main topics of the discussion. After this, the respondents started to communicate more openly. Nonetheless, there is still a possibility that this communication barrier was not completely eliminated for all respondents.

Another limitation of the study is that participants were recruited purposively and belonged to a particular region of Nepal. Therefore, the study population cannot represent all mothers living in other geographical regions of Nepal.

\section{CONCLUSIONS}

We undertook this qualitative study to explore mothers' perceptions of their role in children's diet and physical activity. We collected data in six FGDs from mothers of young children in the JD-HDSS, a peri-urban area of the Kathmandu valley. Our results show widespread misconceptions about healthy food, irrespective of educational level of the respondents, and also reveal mothers' inability to control their children's eating habit. However, participants did not perceive their children's physical activity as very important and thus did not prioritise it.

On the basis of our findings, it is evident that Nepal needs health education programmes to teach mothers of school-age children about diet and physical activity. Although we observed no major differences in knowledge level or preferred method of health intervention, mothers' educational background requires consideration during educational intervention to ensure appropriate and accurate delivery of health education messages to this target audience.

\section{Author affiliations}

${ }^{1}$ Department of Community Medicine, Kathmandu Medical College, Kathmandu, Nepal

${ }^{2}$ Department of Internal Medicine and Clinical Nutrition, Institute of Medicine, Sahlgrenska Academy at University of Gothenburg, Gothenburg, Sweden

${ }^{3}$ Department of Community Health Sciences, Patan Academy of Health Sciences, Lalitpur, Nepal

${ }^{4}$ Department of Public Health and Community Medicine, University of Gothenburg, Gothenburg, Sweden

${ }^{5}$ Department of Biomedicine and Public Health, School of Health and Education, University of Skövde, Skövde, Sweden

${ }^{6}$ Department of Community Medicine, Faculty of Health Sciences, The Arctic University of Norway, Tromsø, Norway

Acknowledgements The authors would like to thank the study participants for their valuable input and time. The help of the local health workers in organising and conducting the study is gratefully acknowledged. They also thank scientific editor Karen Williams (Kwills Editing Services, Weymouth, MA, USA) for providing professional English language editing of this article.

Contributors NO and AV were responsible for the study design, and also collected, analysed and interpreted the data. NO wrote the manuscript. AK, GE and MS were involved in the study planning, discussion during data analysis and interpretation and manuscript review.

Funding The University of Gothenburg provided travel funds to NO through a "Global University" grant.

Competing interests None declared

Ethics approval The Institutional Review Board of Kathmandu Medical College gave ethical permission to conduct this study.

Provenance and peer review Not commissioned; externally peer reviewed.

Data sharing statement No additional data are available.

Open Access This is an Open Access article distributed in accordance with the Creative Commons Attribution Non Commercial (CC BY-NC 4.0) license, which permits others to distribute, remix, adapt, build upon this work noncommercially, and license their derivative works on different terms, provided the original work is properly cited and the use is non-commercial. See: http:// creativecommons.org/licenses/by-nc/4.0/

\section{REFERENCES}

1. World Health Organization. Global status report on noncommunicable diseases2014. Geneva: World Health Organization, 2015.

2. World Health Organization. Preventing chronic diseases: a vital investment. Geneva: World Health Organization, 2005.

3. World Health Organization. Non-communicable diseases country profiles. 2011. http://www.who.int/nmh/countries/npl_en.pdf (accessed 19 Dec 2014).

4. Kohl HW, Craig CL, Lambert EV, et al. The pandemic of physical inactivity: global action for public health. Lancet 2012;380:294-305.

5. Cecchini M, Sassi F, Lauer JA, et al. Tackling of unhealthy diets, physical inactivity, and obesity: health effects and cost-effectiveness. Lancet 2010;376:1775-84. 
6. Moodie R, Stuckler D, Monteiro C, et al. Profits and pandemics: prevention of harmful effects of tobacco, alcohol, and ultra-processed food and drink industries. Lancet 2013;381:670-9.

7. World Health Organization. Diet, nutrition and prevention of chronic disease. Geneva: World Health Organization, 2003.

8. Popkin BM. The shift in stages of the nutrition transition in the developing world differs from past experiences. Public Health Nutr 2002;5:205-14

9. Vaidya A. Tackling cardiovascular health and disease in Nepal: epidemiology, strategies and implementation. Heart Asia 2011;3:87-91.

10. Nepal Health Research Council. Prevalence of non-communicable disease in Nepal: Hospital-based study. Kathmandu: Nepal Health Research Council, 2010.

11. Oli N. Risk of heart disease. http://www.thehimalayantimes.com/ fullTodays. php?headline=Risk+of+heart+disease+\&NewsID=429142 (accessed 30 Sep 2014)

12. Oli N, Vaidya A, Thapa G. Behavioural risk factors of noncommunicable diseases among Nepalese urban poor: a descriptive study from a slum area of Kathmandu. Epidemiol Res Int 2013. doi.org/10.1155/2013/329156

13. Aryal UR, Vaidya A, Shakya-Vaidya S, et al. Establishing a health demographic surveillance site in Bhaktapur district, Nepal: initial experiences and findings. BMC Res Notes 2012;5:489.

14. Vaidya A, Oli N, Aryal UR, et al. Disparities in fruit and vegetable intake by socio-demographic characteristics in peri-urban Nepalese adults: findings from the Heart-Health Associated Research and Dissemination in the Community (HARDIC) Study, Bhaktapur, Nepal. J Kathmandu Med Coll 2013;2:3-11.

15. Vaidya A, Aryal UR, Krettek A. Cardiovascular health knowledge, attitude and practice/behaviour in an urbanising community of Nepal: a population-based cross-sectional study from Jhaukhel-Duwakot Health Demographic Surveillance Site. BMJ open 2013;3:e002976.

16. Oli N, Vaidya A, Subedi M, et al. Experiences and perceptions about cause and prevention of cardiovascular disease among people with cardiometabolic conditions: findings of in-depth interviews from a peri-urban Nepalese community. Glob health action 2014;7:24023.

17. Nutbeam D, Harris E, Harris E. Theory in a nutshell: a guide to health promotion theory. Sydney: McGraw-Hill, 1999.

18. World Health Organization. Global Atlas on cardiovascular disease prevention and control. Geneva: World Health Organization, 2011.

19. Magnussen $C G$, Niinikoski $H$, Juonala $M$, et al. When and how to start prevention of atherosclerosis? Lessons from the Cardiovascular Risk in the Young Finns Study and the Special Turku Coronary Risk Factor Intervention Project. Pediatr Nephrol 2012;27:1441-52.

20. Fagot-Campagna A, Narayan KM, Imperatore G. Type 2 diabetes in children. BMJ 2001;322:377-8.

21. Aryal KK, Neupane S, Mehata S, et al. Non communicable diseases risk factors: STEPS Survey Nepal 2013. Kathmandu: Nepal Health Research Council, 2014.

22. Hendrie GA, Coveney J, Cox DN. Defining the complexity of childhood obesity and related behaviours within the family environment using structural equation modelling. Public Health Nutr 2012;15:48-57.

23. Hart KH, Herriot A, Bishop JA, et al. Promoting healthy diet and exercise patterns amongst primary school children: a qualitative investigation of parental perspectives. J Hum Nutr Diet 2003;16:89-96.

24. Hendrie G, Sohonpal G, Lange $\mathrm{K}$, et al. Change in the family food environment is associated with positive dietary change in children. Int J Behav Nutr Phys Act 2013;10:4.

25. Al-Shookri A, Al-Shukaily L, Hassan F, et al. Effect of mothers nutritional knowledge and attitudes on Omani children's dietary intake. Oman Med J 2011;26:253-7.

26. Vereecken C, Maes L. Young children's dietary habits and associations with the mothers' nutritional knowledge and attitudes. Appetite 2010;54:44-51.

27. Pearson N, Timperio A, Salmon J, et al. Family influences on children's physical activity and fruit and vegetable consumption. Int $J$ Behav Nutr Phys Act 2009;6:34

28. Tamang S. Legalizing state patriarchy in Nepal. Stud Nepali Hist Soc 2000;5:127-56.

29. Winham DM. Culturally tailored foods and CVD prevention. Am J Lifestyle Med 2009;3:64s-8s.

30. Glanz K, Viswanath K. Health behavior and health education: Theory, research, and practice. 4th edn. San Francisco: Jossey-Bass, 2008.
31. Krummel DA, Humphries D, Tessaro I. Focus groups on cardiovascular health in rural women: implications for practice. $J$ Nutr Educ Behav 2002;34:38-46.

32. Sosa ET. Mexican American mothers' perceptions of childhood obesity: a theory-guided systematic literature review. Health Educ Behav 2012;39:396-404

33. Farahmand $\mathrm{M}$, Tehrani FR, Amiri $\mathrm{P}$, et al. Barriers to healthy nutrition: perceptions and experiences of Iranian women. BMC Public Health 2012;12:1064.

34. Wong LP. Focus group discussion: a tool for health and medical research. Singapore Med J 2008;49:256-60.

35. Schreier M. Qualitative content analysis in practice. London: SAGE, 2012.

36. Graneheim UH, Lundman B. Qualitative content analysis in nursing research: concepts, procedures and measures to achieve trustworthiness. Nurs Educ Today 2004;24:105-12.

37. Food and Agriculture Organization of the United Nations. Assessment of Food Security and Nutrition Situation in Nepal. ftp:// ftp.fao.org/TC/CPF/Country\%20NMTPF/Nepal/thematic\%20studies/ Food\%20Security\%20_Final_.pdf (accessed 5 Feb 2015).

38. Paschim Paaila. Food hygiene practice in Nepal; an experience from formative research.WASH Forum 25th Series. Secondary "Food Hygiene Practice in Nepal; an Experience from Formative Research: WASH Forum 25th Series. http://paschim-paaila.blogspot.com/2013/ 09/food-hygiene-practice-in-nepal_3.html (accessed 5 Feb 2015).

39. Pradhan B. Rural communities' perception on water quality and water borne disease: the case of Bugamati village development committee in Kathmandu valley, Nepal. J Nepal Health Res Counc 2008;2:2-7.

40. Nepal Water For Health. Many people's health in Jiya Bahadur's hands. http://newah.org.np/index1.php?option=information\&id=181 (accessed 5 Feb 2015)

41. Rotter JB. Internal versus external control of reinforcement: a case history of a variable. Am Psychol 1990;45:489-93.

42. Chapman K, Ogden J. How do people change their diet?: an exploration into mechanisms of dietary change. J Health Psychol 2009;14:1229-42.

43. Galvez P, Valencia A, Palomino AM, et al. Communicating about eating behaviors: a qualitative study of Chilean women and their health-care providers. Int J Qual Stud Health Well-being 2015;10:25979.

44. Pettigrew S. Mothers' perceptions of their control over their children's diets. Adv Consum Res 2007;34:306-11.

45. Raberg Kjollesdal MK, Telle Hjellset V, Bjorge B, et al. Barriers to healthy eating among Norwegian-Pakistani women participating in a culturally adapted intervention. Scand $J$ of Public Health 2010;38(5 Suppl):52-9.

46. Thompson SC, Schlehofer MM. Perceived control. http:// cancercontrol.cancer.gov/Brp/constructs/perceived_control/ perceived control.pdf (assessed 12 Jan 2015).

47. Bisogni CA, Jastran M, Seligson M, et al. How people interpret healthy eating: contributions of qualitative research. J Nutr Educ Behav 2012:44:282-301.

48. De Lira-García C, Bacardí-Gascón M, Jiménez-Cruz A. Preferences of healthy and unhealthy foods among 3 to 4 year old children in Mexico. Asia Pac J Clin Nutr 2012;21:57-63.

49. Haerens L, De Bourdeaudhuij I, Barba G, et al. Developing the IDEFICS community-based intervention program to enhance eating behaviors in 2- to 8-year-old children: findings from focus groups with children and parents. Health Educ Res 2009;24:381-93.

50. Bentley GF, Goodred JK, Jago R, et al. Parents' views on child physical activity and their implications for physical activity parenting interventions: a qualitative study. BMC Pediatr 2012;12:180.

51. Beets MW, Cardinal BJ, Alderman BL. Parental social support and the physical activity-related behaviors of youth: a review. Health Educ Behav 2010;37:621-44.

52. Vaidya A, Krettek A. Physical activity level and its sociodemographic correlates in a peri-urban Nepalese population: a cross-sectional study from the Jhaukhel-Duwakot health demographic surveillance site. Int J Behav Nutr Phys Act 2014;11:39.

53. Nixon CA, Moore HJ, Douthwaite W, et al. Identifying effective behavioural models and behaviour change strategies underpinning preschool- and school-based obesity prevention interventions aimed at 4-6-year-olds: a systematic review. Obes Rev 2012;13(Suppl 1): $106-17$. 